\title{
Public Perceptions About the Impact of Climate Change on Human Health: A Study of Bangladesh
}

\author{
Bikram Biswas ${ }^{1 *}$, Sajib Kumar Roy ${ }^{2}$, Mohammad Nur Ullah ${ }^{3}$, Shanjay Kumar Mukharjee ${ }^{4}$
}

\author{
${ }^{1}$ Noakhali Science and Technology University, BANGLADESH \\ ${ }^{2}$ Hajee Mohammad Danesh Science and Technology University, BANGLADESH \\ ${ }^{3}$ Bangladesh University of Professionals, BANGLADESH \\ ${ }^{4}$ Jatiya Kabi Kazi Nazrul Islam University, BANGLADESH \\ *Corresponding Author: bikramju1020@gmail.com
}

Citation: Biswas, B., Roy, S. K., Ullah, M.N., \& Mukharjee, S. K. (2021). Public Perceptions About the Impact of Climate Change on Human Health: A Study of Bangladesh. Aquademia, 5(2), ep21012. https://doi.org/10.21601/aquademia/11445

\section{ARTICLE INFO}

Received: 20 Sep. 2021

Accepted: 18 Nov. 2021

\begin{abstract}
The main purpose of this research is to analyze the perception of climate change impacts on human health in Bangladesh through data from nationality representative surveys conducted in some district of Bangladesh. In Bangladesh there have a few research has been conducted on public perceptions about the impact of climate change on human health. A structured questionnaire method was conducted, and data collected from 615 respondents. The findings of this study reveal that out of 615 respondents, $76.0 \%$ of the respondents replied positively while remaining $24.0 \%$, almost one-fourth of total respondents, indicated that they have not heard the term climate change before. Knowledgeable in climate change, $92.5 \%$ of respondents agreed that climate change has an impact on human health while only $7.5 \%$ respondents disagreed with this statement. $90.5 \%$ of respondents argued that they are agreed with the opinion that climate change is a serious threat to human health. This study will contribute informatively to the scant information on the impacts of climate change affecting human health in Bangladesh. Theoretically, the study will also contribute to the previous literature on the public perceptions of climate change impacts on human health. Furthermore, the results of the study will be very useful for climate change policy makers, especially Ministry of Environment and Forest (MoEF) for the making related policies and mechanisms in order to overcome with current human health impacts in Bangladesh. In addition, the awareness of existence, the impacts, and the causes of climate change will be possible to integrate climate change into policy planning, projects and daily activities as well as make the whole society to participate in the entire process to mitigate climate change.
\end{abstract}

Keywords: public perception, climate change, human health, Bangladesh

\section{INTRODUCTION}

Bangladesh is a densely-populated, mainly riverine and low-laying country located in South Asia. The country's total land size is 147,570 square kilometers (Bangladesh Bureau of Statistics (BBS, 2019a), which is relatively small compare to its neighbor. The environmental issue is currently one of the most significant issues on the global political and economic agendas. People from impoverished section are being the most helpless because of the impact of environmental issues. On the other hand, In Bangladesh, the environmental issues lower the value of and excess to productive resources and create health problems as well mainly for the poor, which increases vulnerability and complicate economic growth and poverty alleviation process. The climate of Bangladesh is a subtropical monsoon climate and characterized by wet and dry seasons. Particularly, Winter, Summer, and Monsoon are prominent among the six seasons in a year in this country. In winter, generally from November to February, the minimum temperature fluctuates within the range from 7 degrees Celsius to 13 degrees Celsius where the maximum temperature in this season surges within the range from 24 degrees Celsius to 31 degrees Celsius. In Summer (March - June), the average maximum temperature is 37 degrees Celsius because the temperature sporadically rises up to 41 degrees Celsius or more in some places in this season. $80 \%$ of the total rainfall occurs in the Monsoon period which usually starts in July and stays up to October, while the average annual rainfall differs from 1429 to 4338 millimeters. The maximum rainfall is observed in the northern part of Sylhet and the coastal areas of Chattogram, whereas the lowest rainfall is recorded in the northern and western regions of Bangladesh (BBS, 2019b). Bangladesh faces nearly all kinds of natural disasters including drought, heavy rain, floods, heavy storms, riverbank collapse, fire incident and epidemics on a regular basis that affect 
people as well as their belongings over and over again all most every single year and put the economy of the country in extremely dangerous position (Oudry et al., 2016).

Bangladesh has done poorly in the 2020 edition of a recent environment report, ranking dismal 162 out of 180 countries worldwide; the country returned one of the lowest environmental performance index scores in the region (EPI, 2020). The government of Bangladesh has paid deep consideration for a long time not only at the national level but also at the regional levels with the aim of addressing the challenges emerged as a result of climate change. Moreover, Bangladesh has acknowledged the significance of protecting the environment and effect of climate change in its efforts towards economic advancement (MoEFCC, 2018). Besides, climate-change-induced issues on biological diversity in Bangladesh is still to be defined but likely to prompt major changes in ecosystems and to the livelihoods of rural communities who are greatly dependent on natural resources for their survival (MoEFCC, 2018). It seems that only a few studies regarding public awareness and understanding the impacts and risks of climate change on human health have been conducted so far and almost neither of which has been published or synthesized. Furthermore, citizens of developing countries were more concerned about the impacts of climate change on health than the citizens of developed countries (Akerlof et al., 2010). The considerable impacts caused by climate change are expected to affect human health in many ways such as various diseases like growing number of foodborne, vector-borne and water-borne diseases, as well as deaths and injuries as a consequence of heat-related diseases and extreme hydro-geological events, deaths resulting from heat waves and malnutrition as a result of negative impacts of global climate change (Markandya \& Chiabai, 2009). This research explored to find out the public understanding on changes in climate in the context of Bangladesh, public awareness and perceptions about climate change affecting human health, to figure out the perception regarding the correlation between climate change and diseases as well as to find out the public attitudes towards climate change policies of Bangladesh.

\section{LITERATURE REVIEW}

Public Perception (PP) is known as the social phenomenon. PP may be viewed as the differences between what really happened on the basis of evidence and virtual truth framed depending on popular sentiment, coverage of media and reputation. Similarly, PP is simply defined as the type of information obtained from a survey of public opinion which is simply represents a group of individuals' collective thoughts about any particular events or issues (Dowler et al., 2006). Besides, based on business dictionary, "perception is defined as the process by which people translate sensory impressions into a coherent and unified view of the world around them though necessarily based on incomplete and unverified information, perception is equated with reality for most practical purpose and guides human behavior in general". On the other hand, Cambridge Dictionary defined perception "as a belief or opinion, often held by many people and based on how things seem; or the quality of being aware of things through the physical senses, especially sight; also defined as someone's ability to notice and understand things that are obvious to other people".

Climate Change (CC) stands for a variance in climate patterns which might be determined by its properties' inconsistency or fluctuations in the average which continues for a specific period of time, especially for several decades. CC may happen because of various natural as well as external factors responsible for the changes in atmosphere or land use composition. The climate is the typical or average weather of any local areas or regions, so the changing nature of any city or region's average or typical weather may be described as the change in climate of that specific location; for example, it may be a change in any area's average temperature for a specific period of time or a change in any region's yearly average rainfall patterns. Moreover, CC is also explained as any long term change in climate in Earth; it may be the changing pattern of global average temperature or annual rainfall patterns in Earth. In contrast, climate change impacts (CCI) discuss about the consequences of the changes in climate on both natural and human arrangements; CCIs include potential impacts, residual impacts, aggregate impacts, market and nonmarket impacts (Bose, 2017). CC means a variance in climate due to human activities which is directly or indirectly responsible for the changes in the composition of global atmosphere (Protocol, 1997). In addition, inconsistency in natural climate also observed at the same time period (Protocol, 1997).

Human Health $(\mathrm{HH})$ is a complete state of mental, physical and social well-being and not only the nonexistence of ailment or decrepitude (WHO, 1948). Its definitions present three major interrelated health components; the physiological refers to the functionality of the biological system while mental focus on the emotional, psychological and intellectual state of human; in addition, social wellbeing refers to the connecting ability as well as the function of as society member (Amzat \& Razum, 2014). Saracci (1997) defined health as "a condition of well-being, free of disease or infirmity and a basic and universal human rights." Implicitly, ailing people who are living confidently despite their chronic disorder are considered through this definition. Furthermore, the Cambridge Dictionary defined the term health as the condition of the body and degree to which it is free from illness or the state of being well. On one hand, health was defined as, "a dynamic state of well-being characterized by a physical and mental potential, which satisfies the demand of life commensurate with age, culture and personal responsibility" (Bircher, 2005). Good health is vital in alleviating poverty because the presence of bad health may lead someone to be poverty stricken.

\section{Impacts of Climate Change}

\section{World Perspective}

Alhassan and Hadwen (2017) mentioned that facilities and services regarding water, sanitation and hygiene are being threatened by climate change now-a-days as well as droughts and floods are reducing water supply and polluting water respectively on the basis of their observation in northern areas of Ghana where the residents of this region are facing serious problems to deal with these perennial issues. Moreover, both 
surface water and underground water are being affected by CC (Alhassan \& Hadwen, 2017). In Romania, the rising concern includes the impact of the changes in climate on its forestry, agriculture, human settlements and water management (Teodorescu \& Oros, 2010). CC impacts on river discharge are vitally important in Ukraine; the results indicate the temperature increases and river discharge will increase because of earlier snowmelt during winter as well as decrease all through the spring (Didovets et al., 2017).

Moreover, human health is being threatened significantly especially by contagious diseases spreading out as a result of climate change. Markandya and Chibai (2009) mentioned that the huge implications of CC for the health of human being consist of calorific linked disease incidence because of lifethreatening temperatures, effects related to pollution of the air, impacts of extreme weather patterns, dietary deficiency, aqueous diseases and vector-borne diseases. Direct impacts of CC on human health lead to injuries illness, and death of human due to thrilling weather patterns as well as growing number of infectious diseases because of variations in weather patterns whereas indirect impacts of food scarcity, lack of nutrition, loss of livelihoods and shifting of living place lead to negative health effects (Akerlof et al., 2015).

Chhinh and Cheb (2013) measured the vulnerability of household due to the changes in climate among communities in Kampong Speu Province (KSP), Cambodia by using three indicators including adaptive capacity, sensitivity and exposure while the exposure was quite low. The results of the survey from 630 households showed that drought is the pronoun hazard in KSP whereas livelihood and infrastructure are more sensitive. Besides, households are living in highland seem to be more vulnerable than low land residents (Chhinh \& Cheb, 2013). Chhinh and Poch (2012) found that over sixty percent households of KSP are in serious danger due to the changes in climate as well as drought poses significant threat among the natural calamities exposed in Cambodia. Uniquely, a study by Chean (2017) found that the farmers had little knowledge and understanding of CC and its adaptation strategies in Takeo Province while they had good perceptions of risk and adverse impacts of severe atmospheric conditions on their health, food, life and economic activities. Further results demonstrated that some health-related issues such as heat-related stress, anxiety, and concern were caused by extreme weather events. On the other hand, Bangladesh is in a vulnerable position at present time due to natural disasters such as flood, drought, windstorm etc. and the frequency and severity level of these natural hazards have been increased from the year of 1988 from when statistical information has been recorded on a regular basis. As a result, the economy of Bangladesh and livelihood of its people as well as its socioeconomic structure have severely affected due to natural calamities and extreme climate conditions (Sour et al., 2014).

Furthermore, there are some studies conducted in different countries around the world on public awareness about the changes in climate. For instance, a study carried out by Tvinnereim et al. (2017) confirmed that Chinese respondents seem that the change in climate has negative influence on humans, and most of them are aware of the difference between the physical manifestation of air pollution and global warming responsible for smog and sea-level rise. Likewise, Toan et al.
(2014) identified headaches, tiredness and motion sickness as well as high blood pressure and other diseases affecting the heart and blood vessel as the most common symptoms found in human body due to climate change; additionally, most of the respondents as well as inhabitants of Hanoi, Vietnam had listened about the changes in climate and its impacts on the health of human being. Growing evidence suggested that the changes in climate affects the health of human being of South Asian least developed countries (LDCs) through increased incidence of floods, storms, droughts and fires, and the people of some LDCs like Lao PDR, Cambodia of South-east Asia have been severely affecting because of growing intensity of droughts resulting untimely and changing rainfall patterns (Miyan, 2015). As like, Pillay and van den Bergh (2016) also confirmed that human health was seriously affected by storms, floods, and droughts as production of food and supply of water are restricted by these disasters.

Al Buloshi and Ramadan (2015) conducted a study on the inhabitants living in Muscat governorate region of Oman and studied on people's knowledge and consciousness about the changes in climate by using descriptive statistics as the key investigation technique where they mentioned that awareness level of public about the changes in climate is high enough despite knowledge deficiency regarding the reasons of climate change and preventive measures to tackle the changes in climate. Furthermore, regression analysis resulted that the important determinants that fix the level of awareness are gender, year of education, and income; anyway, the result also indicated that majority of those interviewed are fairly knowledgeable about the changes in climate in Oman (Al Buloshi \& Ramadan, 2015). Nigatu et al. (2014) supported a slightly higher rate in females were conscious about the health issues because of the changes in climate. Public health $(\mathrm{PH})$ is at serious risk because of $\mathrm{CC}$; the barriers to $\mathrm{PH}$ engagement in addressing CC consist of individual perceptions and absence of leadership, authority and capacity of $\mathrm{PH}$; therefore, the efforts to increase the capacity of $\mathrm{PH}$ and to face the changes in climate and inequalities in health, concerned authorities should pay attention to learning and communications, proper funding and leadership building as well as strengthening shared work (Gould \& Rudolph, 2015). Extreme weather and climate events, particularly in the countries of lower and middle income level, are linked with a plethora of consequences for the health such as undernourishment, disorder of mental health, and intensification of chronic ailments; hence, a better understanding of these events is needed (Ebi \& Bowen, 2016). Variance in climate at local level is the probable reason as well as the biggest hindrance in terms of recognizing human activities responsible for the changes in climate (Hansen et al., 2012).

Vardoulakis et al. (2015) focused on building overheating and thermal comfort, quality of room air, indoor anaphylaxis, and contagions as well as damages due to flood and pollution of water in the UK; they found that a section of people at grave danger due to health-related issues include older persons, individual with already existed illness, people dwelling in congested areas and people who are socio-economically underprivileged. Furthermore, events in cold climate conditions in the UK were seen as pointing towards the reality of climate change and the people interpret these events on the 
basis of the levels of already exist negativism about CC (Capstick \& Pidgeon, 2014). McMichael (2013) agreed "environmental researchers must argue for heightened public attention to today's macro-environmental threats to present and future population health by emphasizing on the ecological dimension".

\section{Bangladesh Perspective}

Kabir et al. (2016c) mentioned that livelihood patterns and overall health status of the people of Bangladesh are seriously affected by natural calamities like cyclones, drought, floods etc. occurring frequently due to the changes in climate and its impact. Kabir et al. (2016a) indicated that the marginalized populations of Bangladesh are potentially at risk of climate change in the matter related to their health because they are suffering a lot regarding health issues due to the impacts of climate change and also urged the country's public health care system to take necessary steps regarding adapting the changes in climate and its impact in the future.

Anwer (2012) stated that Bangladesh is frequently experiencing the adverse impacts of the changes in climate like as regular and long-lasting floods, high intensity of cyclones and tidal surges, encroaching salinity, river erosion, etc. that results forced migration of a significant number of people every year throughout the country or beyond borders in search of livelihood based on their connections and contacts with receivers. Ministry of Foreign Affairs (MoFA) of the Netherlands (2018) noted that Bangladesh is in the group of most seriously affected countries because of the changes in climate and inclined to thrilling weather patterns like cyclones, storm surges, floods etc. due to its topography and geographical location where biophysical factors (floods and cyclones prone for being a flat, low, delta country) and socioeconomic factors (such as population density, high dependence on agriculture and poverty) are responsible for its vulnerability.

Shahid (2010) presumed that human health can be affected directly as well as indirectly by climate change in several ways. Due to climate change, people of Bangladesh directly face natural calamities like cyclones, floods, droughts, heat waves, stagnant weather etc. almost every year that causes loss of lives, serious illness, psychological distress, various diseases, etc. On the other hand, people of this country are indirectly affected by various infectious and skin diseases, by the impact of frequent floods, water-logging, variable precipitation, increased breeding of vectors, sea-level rise, groundwater over-exploitation, increased recharge in monsoon and groundwater pollution, droughts and lack of water, hostile conditions, decreased food production and malnutrition. As a result, various types of problems especially problems regarding health issues including life-threatening diseases, skin and infectious diseases, vector-borne diseases, arsenicals etc. break out that suffer people a lot. Uddin et al. (2017) mentioned that the change in climate has severely affected the socio-economic conditions of the farmers on the basis of their observation in the coastal areas of Bangladesh. Due to temperature and salinity level rise, cyclones, droughts, floods, etc. and drop in rainfall, farmers are to suffer a lot at the time of crop production. Javed et al. (2020) found that the health of human being are being directly as well as indirectly affected by salinity level increasing due to adverse climate. People of coastal areas are to suffer from several diseases such as skin diseases, gastric, dysentery, high blood pressure, hair loss, diarrhea, etc. because of using saline water. Javed et al. (2020) also observed that increasing salinity hampers crop cultivation in coastal areas and would be going to a serious threat in terms of availing drinking water as well as water for household uses for the people living in these areas. Haque et al. (2012) revealed that climate variability such as increased heat, reduced rainfall, overall warmer winters, etc. have a negative effect in most cases on matters related to human health, means of living, agriculture, and overall livelihood.

\section{RESEARCH METHODOLOGY}

\section{Research Design}

The study used the quantitative approach to analyze the public perceptions of CC impacts of $\mathrm{HH}$ in Bangladesh. This approach is adopted to capture the CC issues, its main causes, CC impacts on health and PP on CC's policies. This was done by applying the survey questionnaire. The study is largely exploratory, descriptive, and analytical in an attempt to assess the public perceptions of CC impacts on human health in Bangladesh. There were 615 people (based on sample size calculation) in this study who are described according to the data they provided regarding their age, gender, marital status, education, and income level. Our research design is depicted in Figure 1.

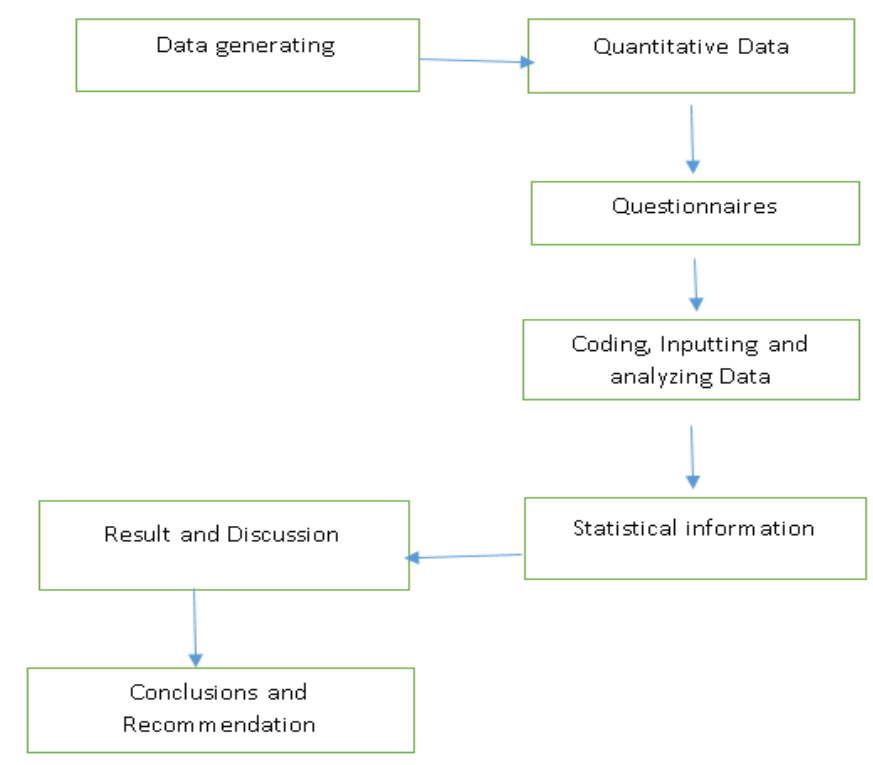

Figure 1. Research design

\section{Study Area}

The study was conducted of ten UPs of ten different UPZs of ten different districts of Khulna, Rajshahi, Rangpur, Dianjpur, Chittagong, Barishal, Kushtia, Dhaka, Comilla, and Maymensingh which selected as the study area around eight divisions in Bangladesh. Figure 2 shows our study area. 


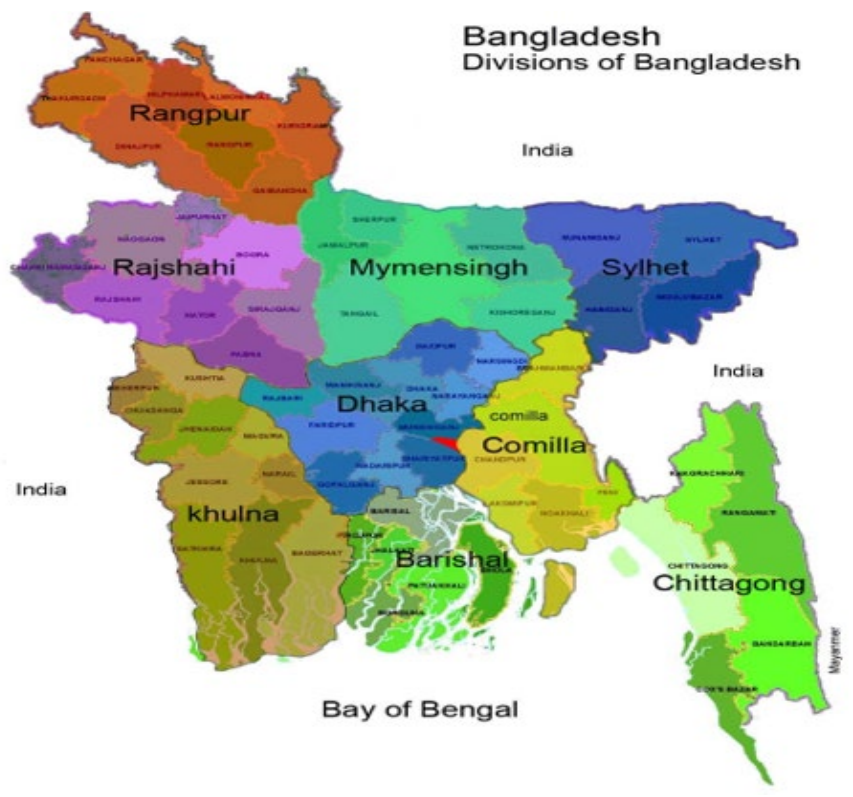

Figure 2. Our study area

\section{Questionnaire Development}

In this study, five-point Likert Scale (1 for Strongly Disagree to 5 for Strongly Agree) will be used for items measurement to express the level of agreement or disagreement and frequency of respondents answer (Biswas et al., 2020). The first dimension comprised of seven items were adapted by Kabir et al. (2016b) and, Twum Barimah (2015) including "Have you heard of CC before?", "What are the main sources of your information on CC?”.

\section{FINDINGS}

\section{Demographic Information of Respondents}

A total of 650 people were randomly selected for interview. Out of them, 615 (94.6\%) people have participated in the process. Table 1 shows the demographic information of respondents. Females' representation (28.3\%) was much lower than in males (71.7\%) in this study. Most of the respondents (38.0\%) belong to 31-40 years' age group, followed by $26.8 \%$ from $21-30$ years age group and the last group's (3.4\%) age was 61 years or higher. Study data reveals that a significant number of respondents (13.7\%) had no education while 30.7\% completed their primary education, followed by $21.5 \%$ who completed graduation, $17.6 \%$ who were able to complete high school education, $12.2 \%$ earned post-graduation degree and the tiniest group (4.4\%) completed college education. People from different categories in terms of their occupation were the respondents of this study where $19.5 \%$ each came from the farmer, student, and day laborer categories, followed by $9.8 \%$ each from teacher, businessman, housewife, and shopkeeper categories, and the remaining $2.4 \%$ consisted of others. $28.8 \%$ of respondents' income range fell between Tk. 5001 to Tk. 10000 , followed by $24.9 \%$ had no income because of being a student or housewife, $23.4 \%$ of respondents' income was equal or less than Tk. 5000 per month, $21.4 \%$ of respondents' income range fell between Tk. 10001 to Tk. 40000 while only 1.5\% of respondents' income was more than Tk. 40000 per month.
Table 1. Demographic information of respondents $(\mathrm{N}=615)$

\begin{tabular}{|c|c|c|}
\hline \multirow{3}{*}{$\begin{array}{l}\text { Variable } \\
\text { Gender }\end{array}$} & & Percentage (\%) \\
\hline & Male & 71.7 \\
\hline & Female & 28.3 \\
\hline \multirow[t]{6}{*}{ Age } & $\leqslant 20$ & 10.7 \\
\hline & $21-30$ & 26.8 \\
\hline & $31-40$ & 38.0 \\
\hline & $41-50$ & 13.2 \\
\hline & $51-60$ & 7.8 \\
\hline & $\geqslant 61$ & 3.4 \\
\hline \multirow[t]{6}{*}{ Level of education } & No education & 13.7 \\
\hline & Primary & 30.7 \\
\hline & High school & 17.6 \\
\hline & College & 4.4 \\
\hline & Bachelor & 21.5 \\
\hline & Masters or above & 12.2 \\
\hline \multirow[t]{8}{*}{ Occupation } & Teacher & 9.8 \\
\hline & Farmer & 19.5 \\
\hline & Businessman & 9.8 \\
\hline & Housewife & 9.8 \\
\hline & Student & 19.5 \\
\hline & Day labourer & 19.5 \\
\hline & Shopkeeper & 9.8 \\
\hline & Others & 2.4 \\
\hline \multirow[t]{5}{*}{ Monthly income (BDT) } & $\leqslant 5000$ & 23.4 \\
\hline & 5001-10000 & 28.8 \\
\hline & $10001-20000$ & 11.2 \\
\hline & $20001-40000$ & 10.2 \\
\hline & $\geqslant 40001$ & 1.5 \\
\hline
\end{tabular}

\section{Knowledge of Climate Change}

This section examined the respondents' knowledge of climate change especially to what extent they have an understanding of this issue. Figure 3 shows the ratio of respondents whether they heard about climate change before or not. The source of their existing knowledge about climate change is shown in Figure 4. Besides, Table 2 represents the cause of climate change, according to respondents' opinion based on five-point Likert Scale (1 for Strongly Disagree to 5 for Strongly Agree).

\section{Heard about climate change before or not $(\mathrm{N}=615)$}

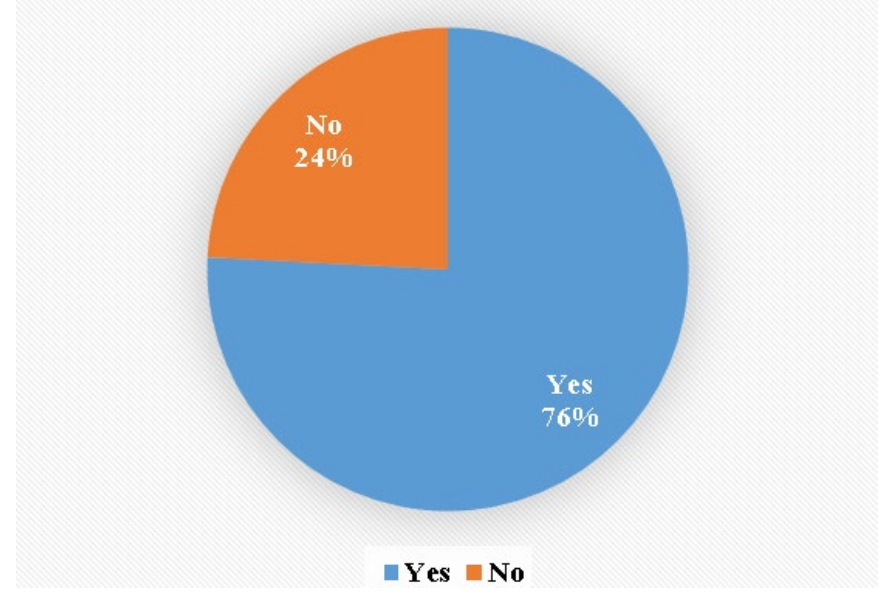

Figure 3. Heard about climate change before or not 
Source of knowledge $(\mathrm{N}=466)$

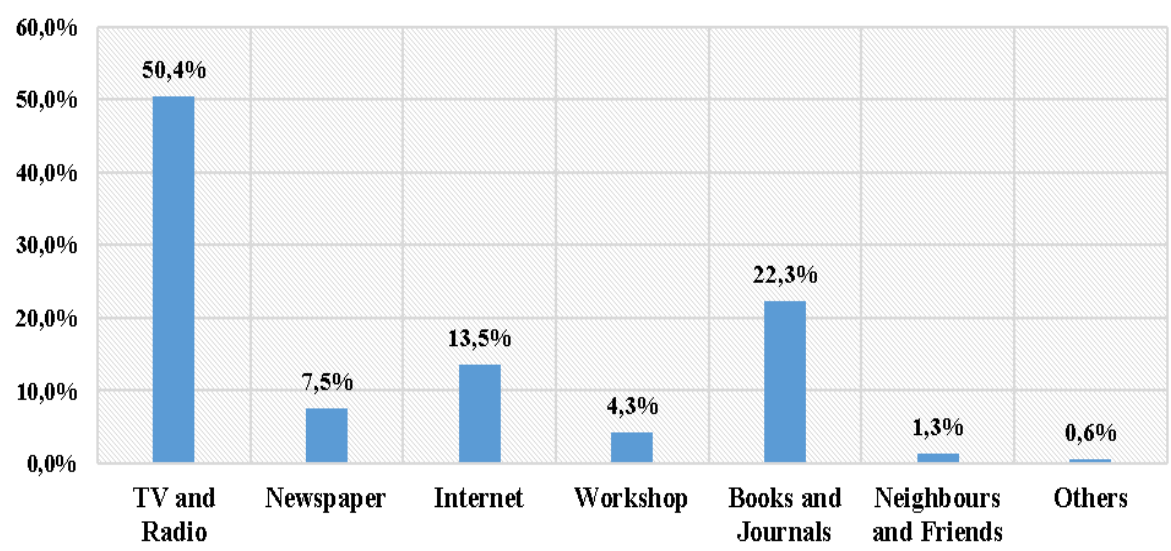

Figure 4. Source of knowledge

Table 2. Cause of climate change

\begin{tabular}{|c|c|c|c|c|c|c|c|}
\hline Opinion $(\mathrm{N}=466)$ & $\begin{array}{c}\text { Strongly } \\
\text { agree }\end{array}$ & Agree & Neutral & Disagree & $\begin{array}{l}\text { Strongly } \\
\text { disagree }\end{array}$ & Mean & SD \\
\hline I think human activities are the main cause of climate change & $33.7 \%$ & $50.9 \%$ & $0.0 \%$ & $12.9 \%$ & $2.6 \%$ & 4.00 & 1.042 \\
\hline I think natural factors are the main cause of climate change & $8.4 \%$ & $39.9 \%$ & $0.0 \%$ & $47.0 \%$ & $4.7 \%$ & 3.00 & 1.181 \\
\hline
\end{tabular}

Table 3. Awareness of climate change impacts on human health $(\mathrm{N}=466)$

\begin{tabular}{|c|c|c|c|c|c|c|c|}
\hline Opinion & $\begin{array}{c}\text { Strongly } \\
\text { agree }\end{array}$ & Agree & Neutral & Disagree & $\begin{array}{l}\text { Strongly } \\
\text { disagree }\end{array}$ & Mean & SD \\
\hline I think climate change has an impact on human health & $42.1 \%$ & $50.4 \%$ & $0.0 \%$ & $7.5 \%$ & $0.0 \%$ & 4.27 & .806 \\
\hline I think climate change is a serious threat to human health & $32.6 \%$ & $57.9 \%$ & $0.0 \%$ & $9.4 \%$ & $0.0 \%$ & 4.14 & .829 \\
\hline $\begin{array}{l}\text { I think extreme heat and cold / diseases / health problems / } \\
\text { sickness will increase }\end{array}$ & $42.7 \%$ & $47.6 \%$ & $0.0 \%$ & $9.2 \%$ & $0.4 \%$ & 4.23 & .885 \\
\hline $\begin{array}{l}\text { I think change in rainfall pattern in the last } 5 \text { years increases } \\
\text { health problem }\end{array}$ & $12.0 \%$ & $63.5 \%$ & $0.0 \%$ & $24.5 \%$ & $0.0 \%$ & 3.63 & .982 \\
\hline I think health risk increased due to increase in salinity & $20.8 \%$ & $55.8 \%$ & $0.0 \%$ & $23.4 \%$ & $0.0 \%$ & 3.74 & 1.039 \\
\hline
\end{tabular}

Table 4. Perception on climate change and diseases $(\mathrm{N}=466)$

\begin{tabular}{|c|c|c|c|c|c|c|c|}
\hline Question & Very high & High & Normal & Low & Very Low & Mean & SD \\
\hline $\begin{array}{l}\text { Q1. What is your overall perception about diseases due to } \\
\text { climate change in Bangladesh? }\end{array}$ & $23.4 \%$ & $51.9 \%$ & $16.1 \%$ & $8.6 \%$ & $0.0 \%$ & 3.90 & .854 \\
\hline $\begin{array}{l}\text { Q2. What is the present frequency of diseases during summer } \\
\text { compared to } 5-10 \text { years earlier? }\end{array}$ & $7.7 \%$ & $55.6 \%$ & $26.2 \%$ & $10.5 \%$ & $0.0 \%$ & 3.61 & .778 \\
\hline $\begin{array}{l}\text { Q3. What is the present frequency of diseases during winter } \\
\text { compared to } 5-10 \text { years ago? }\end{array}$ & $10.5 \%$ & $56.4 \%$ & $23.6 \%$ & $9.4 \%$ & $0.0 \%$ & 3.68 & .786 \\
\hline $\begin{array}{l}\text { Q4. What is the present frequency of diseases during rainy } \\
\text { seasons compared to } 5-10 \text { years ago? }\end{array}$ & $4.1 \%$ & $56.0 \%$ & $29.4 \%$ & $10.5 \%$ & $0.0 \%$ & 3.54 & .736 \\
\hline
\end{tabular}

Table 5. Attitudes towards climate change policies $(\mathrm{N}=466)$

\begin{tabular}{|c|c|c|c|c|c|c|c|}
\hline Opinion & $\begin{array}{c}\text { Strongly } \\
\text { agree }\end{array}$ & Agree & Neutral & Disagree & $\begin{array}{l}\text { Strongly } \\
\text { disagree }\end{array}$ & Mean & SD \\
\hline $\begin{array}{l}\text { The government can take active measures responding to } \\
\text { climate change }\end{array}$ & $18.9 \%$ & $67.0 \%$ & $0.0 \%$ & $13.3 \%$ & $0.9 \%$ & 3.90 & .888 \\
\hline $\begin{array}{l}\text { Fiscal and taxation policies can play a positive role in dealing } \\
\text { with climate change }\end{array}$ & $14.4 \%$ & $67.4 \%$ & $0.0 \%$ & $16.1 \%$ & $2.1 \%$ & 3.76 & .961 \\
\hline $\begin{array}{l}\text { am satisfied with the government and emergency relief } \\
\text { organizations' response to climate change impacts }\end{array}$ & $4.1 \%$ & $39.3 \%$ & $0.0 \%$ & $48.5 \%$ & $8.2 \%$ & 2.83 & 1.157 \\
\hline Personal behavior is important to respond climate change & $18.7 \%$ & $50.6 \%$ & $0.0 \%$ & $29.0 \%$ & $1.7 \%$ & 3.56 & 1.143 \\
\hline I can make contribution to cope with climate change & $17.2 \%$ & $56.2 \%$ & $0.0 \%$ & $24.0 \%$ & $2.6 \%$ & 3.61 & 1.104 \\
\hline
\end{tabular}

\section{Perception About the Impact of Climate Change}

This section measured the respondents' perception about climate-change-induced impacts especially their awareness level about the impact of climate change on human health (Table 3), their perception of climate change and diseases
(Table 4), and their attitudes towards climate change policies (Table 5). In matter related to perception-based questions (1 for strongly disagree to 5 for strongly agree or 1 for very low to 5 for very high) percentage has been used to illustrate the actual scenario. Similarly, mean symbolizes the general average of responses provided by the respondents, while 
standard deviation specifies the variance of replies provided by the respondents to a query differ or diverge from the mean. In most of the cases, standard deviation's value is close to 1 , as displayed in Table 3, Table 4, and Table 5, which indicates each question's response not far from the average.

\section{DISCUSSION}

\section{Knowledge of Climate Change}

\section{Heard about climate change before or not}

Though the study aims to assess the public perception about the impact of climate change on human health in the context of Bangladesh, it was necessary to know whether the respondents have knowledge about climate change and particularly if they have heard about climate change before. In response, $76.0 \%$ of the respondents replied positively while remaining $24.0 \%$, almost one-fourth of total respondents, indicated that they have not heard the term climate change before though all depend on the education level of the people (Figure 3) which demands special attention for informing the unknown about the issue so that they can be able to take precautionary measures to save themselves from the harmful effect of climate change. (Carew-Reid, 2008). When asked them about their understanding of various types of changes in climate, they mentioned global warming, deforestation, temperature rise, drought, heat wave, etc. in response. They also pointed out some problems such as physical and mental health hazard, sea-level rise, deterioration of environmental ecosystem, excessive rain, extreme weather, increasing diseases and illness, natural disaster, etc. will take place due to the changes in climate while talking about the impact of climate change.

\section{Source of knowledge}

Respondents, 466 in number, who have heard about climate change before were also requested to mention the source of their information especially from where they have known about climate change. In reply, more than half of the respondents (50.4\%) mentioned TV (Television), and radio as their source of information while $13.5 \%$ got information about climate change through internet by using their mobile phones or computers which indicates modern technologies like computer, mobile phone, TV, radio, etc. are playing a crucial role to make the unknown people known about any important matter like climate change. Moreover, $22.3 \%$ of respondents knew this matter by reading various books and journals while $7.5 \%$ by reading newspapers. Furthermore, $4.3 \%$ of respondents, particularly farmers, got knowledge of climate change in participating in various workshops arranged by the agriculture extension department or various NGOs working in this field. Besides, $1.3 \%$ came to know the matter from their neighbors and friends, and the remaining $0.6 \%$ from others (Figure 4).

\section{Cause of climate change}

In response to a perception-based question regarding the cause of climate change, majority of the respondents opined that human activities are responsible in this case. Table 2 shows that $84.6 \%$ of respondents agreed on the opinion that human activities are mainly responsible for the changes in climate. On the contrary, less than half of the same respondents (48.3\%) voted in favor of the opinion that natural activities are the main cause of climate change. From this segment, it is clear that people are solely responsible to upgrade or deteriorate the environment through their activities and it is possible to reduce environmental degradation, particularly changes in climate if people behave sensibly.

\section{Perception Regarding the Impact of Changes in Climate}

\section{Awareness of the impact of climate change on human health}

Out of 466 interviewees, knowledgeable in climate change, 92.5\% of respondents agreed that climate change has an impact on human health while only $7.5 \%$ of respondents disagreed with this statement. $90.5 \%$ of respondents argued that they are agreed with the opinion that climate change is a serious threat to human health (Table 3 ) which is much like the outcomes of Toan et al. (2014) and Nigatu et al. (2014) who mentioned that public health is in serious jeopardy because of the changes in climate. Primary data also revealed that $90.3 \%$ of respondents believe that extreme heat and cold /diseases/ health problems /sickness will increase due to climate change, while only $9.6 \%$ respondents opposed the statement. $75.5 \%$ of respondents claimed that changing patterns in rainfall over the past 5 years increases health problems. In addition, $76.6 \%$ of respondents stated that health hazard increased as a result of salinity level rise (Table 3). So, effective steps should be taken as early as possible to face this emerging threat so that public health may be secured.

\section{Perception of climate change and diseases}

Primary data revealed that more than sixty percent of respondents, 466 in number, believe that people of Bangladesh are currently facing more diseases due to climate change than that of 5-10 years ago. In response to the question regarding general understanding about climate-change-induced diseases in Bangladesh, almost three-fourth of total respondents $(74.3 \%)$ marked their reply as high while $16.1 \%$ termed it as normal and the remaining $8.6 \%$ of respondents categorized it as low. In a separate query on season-based disease scenario, $63.3 \%$ of respondents opined that the current rate of diseases in summer months is high in comparison with 5 - 10 years earlier, while $26.2 \%$ mentioned it as normal and $10.5 \%$ labeled it as low (Chaudhary \& Bawa, 2011). In addition, $66.9 \%$ of respondents told that the current frequency of diseases is high in winter season than the frequency of past 5 - 10 years, while $23.6 \%$ of respondents marked it as normal and $9.4 \%$ of respondents figured it as low. Furthermore, $60.1 \%$ of respondents stated that the current prevalence of diseases all through the rainy season is high compared to $5-10$ years ago, while $29.4 \%$ mentioned it as normal and the remaining $10.5 \%$ termed it low (Table 4). So, concerned authorities should take necessary measures in this matter to keep people safe from the diseases break out due to climate change throughout the year.

\section{Attitudes towards climate change policies}

The findings of this research disclosed that $85.9 \%$ out of 466 respondents believe that it is the government which may 
take necessary actions responding to the changes in climate, while $14.2 \%$ of respondents stated the opposite in this case. But the matter of fact that, although the majority respondents have shown their faith on the capacity of government, only $43.4 \%$, almost half of $85.9 \%$, respondents are satisfied with the government and emergency relief organizations' response to climate change impacts at present time, while $56.7 \%$ respondents expressed their dissatisfaction regarding the actions taken by the government and emergency relief organizations. In this case, policies regarding taxation and fiscal can play a positive role to deal with the changes in climate because primary data exposed that $81.8 \%$ of respondents have favored these policies. In addition, $69.4 \%$ of respondents agreed that behavior of individual is significant in responding the changes in climate, while $73.4 \%$ seemed that it is possible for them to play active role in coping with the changes in climate (Table 5).

From the above discussion, it is clear that there is no alternative of awareness-raising among mass people about the changes in climate and its impact on human health and other issues, while ordinary citizens must have to follow the guidelines to keep themselves healthy in spite of climate change as well as people have to come forward to face the impacts regarding the changes in climate. So, time has come for the government and other agencies to rethink and take decisive steps in this regard.

\section{LIMITATIONS AND RECOMMENDATIONS}

This study has some limitations. Firstly, the study was conducted in 10 districts in Bangladesh, which may not represent the overall perceptions of people in Bangladesh. Secondly, this study is based on people's perception which is complicated and difficult to measure.

Policymakers will be better able to establish effective communication strategies for each location in Bangladesh if they understand local opinions and concerns.

The following are the main lessons from this study in this regard: People need more education and awareness to understand that climate change is a public health issue. A high level of understanding of the links between global environmental change and human health may aid the National Climate Change Prevention Program's success. Community groups should be used as climate change communication conduits by the program, especially for the more marginalized groups, such as women and individuals with lower levels of education, who are currently less aware of the challenges.

\section{CONCLUSIONS}

The World Health Organization (WHO) intensified that the change in climate is a crucial and evolving issue to the health of human being and particularly people living in tropical countries or living in lower level of income societies are suffering a lot in this case. Though, the people, especially from Africa and Asia, have merely perceived the change in climate as a serious threat to the health of human being. Bangladesh is one of the few among the countries suffering most for the changes in climate around the globe (Kabir, 2016b). The study explored the public perceptions about the change of climate and its impacts on the health of human in the context of Bangladesh based on lesson learned from South and SouthEast Asian Least Developed Countries (LDCs) like Cambodia, Nepal, Lao PDR, and Bhutan as well as some other countries such as China, UK, USA, India, Canada, Nigeria, Spain, Oman, Poland, and Zimbabwe. This study has also contributed informatively to the scant information on climate-changeinduced impacts affecting the health of human being within the context of Bangladesh. Theoretically, the study has contributed to the existing literature on the public perceptions about the changes in climate and its impacts on the health of human being. Most of the participants had some knowledge about climate change and they stated that both human and natural activities are the causes of the changes in climate while the majority of them believed that climate change has a huge impact on the health of human being than before. Furthermore, the results of the study will be very useful for climate change policymakers especially for the Ministry of Environment, Forest and Climate Change (MoEFCC) for making related policies and mechanisms in order to overcome the current impacts of climate change on the health of human being within the framework of Bangladesh. In addition, awareness regarding climate change, impacts and causes of the changes in climate will have to integrate at the time of formulating climate change related policies or projects as well as include the society as a whole to take part in the process for mitigating the changes in climate. Furthermore, the findings of this study will assist policymakers, development partners, and NGOs working in climate perception to designate the policies and strategic plans to prevent the diseases because of the changes in climate and to promote individuals to address climate change in Bangladesh.

Author contributions: All co-authors have involved in all stages of this study while preparing the final version. They all agree with the results and conclusions.

Funding: No external funding is received for this article.

Declaration of interest: The authors declare that they have no competing interests.

Ethics approval and consent to participate: Not applicable.

Availability of data and materials: All data generated or analyzed during this study are available for sharing when appropriate request is directed to corresponding author.

\section{REFERENCES}

Akerlof, K. L., Delamater, P. L., Boules, C. R., Upperman, C. R., \& Mitchell, C. S. (2015). Vulnerable populations perceive their health as at risk from climate change. International Journal of Environmental Research and Public Health, 12(12), 15419-15433. https://doi.org/10.3390/ijerph121214994

Akerlof, K., Debono, R., Berry, P., Leiserowitz, A., RoserRenouf, C., Clarke, K.-L., Rogaeva, A., Nisbet, M. C., Weathers, M. R., \& Maibach, E. W. (2010). Public perceptions of climate change as a human health risk: Surveys of the United States, Canada and Malta. International Journal of Environmental Research and Public Health, 7(6), 2559-2606. https://doi.org/10.3390/ijerph 7062559 
Al Buloshi, A. S., \& Ramadan, E. (2015). Climate change awareness and perception amongst the inhabitants of Muscat Governorate, Oman. American Journal of Climate Change, 4(04), 330-336. https://doi.org/10.4236/ajcc.2015. 44026

Alhassan, S., \& Hadwen, W. L. (2017). Challenges and opportunities for mainstreaming climate change adaptation into WaSH development planning in Ghana. International Journal of Environmental Research and Public Health, 14(7), 749. https://doi.org/10.3390/ijerph14070749

Amzat, J., \& Razum, O. (2014). Health, disease, and illness as conceptual tools. In Medical Sociology in Africa (pp. 21-37). Springer. https://doi.org/10.1007/978-3-319-03986-2_2

Anwer, S. (2012). Climate refugees in Bangladesh: Understanding the migration process at the local level. Diakonisches Werk der EKD e.V. for "Brot für die welt". https://www.brot-fuerdie-welt.de/fileadmin/mediapool/2_Downloads/Fachinfor mationen/Analyse/analyse_30_englisch_climate_refugees_ in_Bangladesh.pdf

Bangladesh Bureau of Statistics (BBS). (2019a). Statistical pocket book Bangladesh 2018. BBS.

Bangladesh Bureau of Statistics (BBS). (2019b). Statistical year book Bangladesh 2018 (38th Ed.). BBS.

Bircher, J. (2005). Scientific contribution towards a dynamic definition of health and disease. Medicine, Health Care and Philosophy, 81335, 341. https://doi.org/10.1007/s11019005-0538-y

Biswas, B., Roy, S. K., \& Roy, F. (2020). Students perception of mobile learning during COVID-19 in Bangladesh: University student perspective. Aquademia, 4(2), ep20023. https://doi.org/10.29333/aquademia/8443

Bose, P. (2017). Climate adaptation: Marginal populations in the vulnerable regions. Climate and Development, 9(6), 575578. https://doi.org/10.1080/17565529.2017.1318747

Capstick, S. B., \& Pidgeon, N. F. (2014). Public perception of cold weather events as evidence for and against climate change. Climatic Change, 122(4), 695-708. https://doi.org/10.1007/s10584-013-1003-1

Carew-Reid, J. (2008). Rapid assessment of the extent and impact of sea level rise in Vietnam. https://icem.com.au/portfolioitems/rapid-assessment-of-the-extent-and-impact-ofsea-level-rise-in-vietnam-2/

Chaudhary, P., \& Bawa, K. S. (2011). Local perceptions of climate change validated by scientific evidence in the Himalayas. Biology Letters, 7(5), 767-770. https://doi.org/ 10.1098/rsbl.2011.0269

Chean, R. (2017). Perceptions, attitudes and behaviour around climate change risks on livelihood activities: A case study of a community in Takeo Province, Cambodia. https:// researcharchive.vuw.ac.nz/xmlui/handle/10063/6409

Chhinh, N., \& Cheb, H. (2013). Climate change vulnerability: Households assessment level in Kampong Speu Province, Cambodia. International Society of Environmental and Rural Development, 3(2), 31-38.
Chhinh, N., \& Poch, B. (2012). Climate change impacts on agriculture and vulnerability as expected poverty of Kampong Speu Province, Cambodia. International Journal of Environmental and Rural Development, 3(2), 28-37.

Didovets, I., Lobanova, A., Bronstert, A., Snizhko, S., Maule, C. F., \& Krysanova, V. (2017). Assessment of climate change impacts on water resources in three representative Ukrainian catchments using eco-hydrological modelling. Water, 9(3), 204. https://doi.org/10.3390/w9030204

Dowler, E., Bauer, M. W., Green, J. M., \& Gasperoni, G. (2006). Assessing public perception: Issues and methods. In: C. Dora (Ed.). Health, hazards and public debate: Lessons from $B S E / C J D$ saga. WHO Regional Office for Europe, Copenhagen.

Ebi, K. L., \& Bowen, K. (2016). Extreme events as sources of health vulnerability: Drought as an example. Weather and Climate Extremes, 11, 95-102. https://doi.org/10.1016/ j.wace.2015.10.001

Environmental Performance Index (EPI). (2020). https://epi.yale.edu/epi-results/2020/component/epi

Gould, S., \& Rudolph, L. (2015). Challenges and opportunities for advancing work on climate change and public health. International Journal of Environmental Research and Public Health, 12(12), 15649-15672. https://doi.org/10.3390/ ijerph121215010

Hansen, J., Sato, M., \& Ruedy, R. (2012). Perception of climate change. Proceedings of the National Academy of Sciences of the United States of America, 109(37), E2415-E2423. https://doi.org/10.1073/pnas.1205276109

Haque, M. A., Yamamoto, S. S., Malik, A. A., \& Sauerborn, R., (2012). Households' perception of climate change and human health risks: A community perspective. Environmental Health, 11(1), 1. https://doi.org/10.1186/ 1476-069X-11-1

Jabed, M. A., Paul, A., \& Nath, T. K. (2020). Peoples' perception of the water salinity impacts on human health: A case study in South-Eastern Coastal Region of Bangladesh. Exposure and Health, 12, 41-50. https://doi.org/10.1007/s12403-0180283-0

Kabir, M. I., Rahman, M. B., Smith, W., Lusha, M. A. F., \& Milton, A. H. (2016a). Climate change and health in Bangladesh: A baseline cross-sectional survey. Global Health Action, 9(1), 29609. https://doi.org/10.3402/ gha.v9.29609

Kabir, M. I., Rahman, M. B., Smith, W., Lusha, M. A. F., Azim, S., \& Milton, A. H. (2016b). Knowledge and perception about climate change and human health: Findings from a baseline survey among vulnerable communities in Bangladesh. BMC Public Health, 16(1), p.266. https://doi.org/10.1186/s12889-016-2930-3

Kabir, R., Khan, H. T. A., Ball, E., \& Caldwell, K. (2016c). Climate change impact: The experience of the coastal areas of Bangladesh affected by cyclones Sidr and Aila. Journal of Environmental and Public Health, 2016, p.9. https://doi.org/10.1155/2016/9654753 
Markandya, A., \& Chiabai, A. (2009). Valuing climate change impacts on human health: empirical evidence from the literature. International Journal of Environmental Research and Public Health, 6(2), 759-786. https://doi.org/10.3390/ ijerph6020759

McMichael, A. J. (2013). Globalization, climate change, and human health. New England Journal of Medicine, 368(14), 1335-1343. https://doi.org/10.1056/NEJMra1109341

Ministry of Environment, Forest and Climate Change (MoEFCC). (2018). https://moef.gov.bd/

Ministry of Foreign Affairs. (2018). Climate change profile: Bangladesh. https://reliefweb.int/report/bangladesh/clima te-change-profile-bangladesh

Miyan, M. A. (2015). Droughts in Asian least developed countries: Vulnerability and sustainability. Weather and Climate Extremes, 7, 8-23. https://doi.org/10.1016/ j.wace.2014.06.003

Nigatu, A. S., Asamoah, B. O., \& Kloos, H. (2014). Knowledge and perceptions about the health impact of climate change among health sciences students in Ethiopia: A crosssectional study. BMC Public Health, 14(1), 1-10. https://doi.org/10.1186/1471-2458-14-587

Oudry, G., Pak, K., \& Chea, C. (2016). Assessing vulnerabilities and Responses to environmental changes in Cambodia. International Organization for Migration, Phnom Penh.

Protocol, K. (1997). United Nations framework convention on climate change. Kyoto Protocol, Kyoto, 19, 497.

Saracci, R. (1997). The World Health Organisation needs to reconsider its definition of health. BMJ, 314(7091), 1409. https://doi.org/10.1136/bmj.314.7091.1409

Shahid, S. (2010). Probable impacts of climate change on public health in Bangladesh. Asia Pacific Journal of Public Health, 22(3), 310-319. https://doi.org/10.1177/ 1010539509335499
Sour, K., Phalla, C., Sovannarith, S., Sean Somatra, K., \& Sokhem, P. (2014). Methods and tools applied for climate change vulnerability and adaptation assessment in Cambodia's Tonle Sap Basin. https://cdri.org.kh/storage/ pdf/wp97e_1617793043.pdf

Teodorescu, G., \& Oros, C. (2010). Development of education on environmental and climate change impacts in Romania. Procedia-Social and Behavioral Sciences, 2(2), 5502-5506. https://doi.org/10.1016/j.sbspro.2010.03.897

Toan, D. T. T., Kien, V. D., Giang, K. B., Minh, H. V., \& Wright, P. (2014). Perceptions of climate change and its impact on human health: An integrated quantitative and qualitative approach. Global Health Action, 7(1), 23025. https://doi.org/10.3402/gha.v7.23025

Tvinnereim, E., Liu, X., \& Jamelske, E. M. (2017). Public perceptions of air pollution and climate change: Different manifestations, similar causes, and concerns. Climatic Change, 140(3-4), 399-412. https://doi.org/10.1007/ s10584-016-1871-2

Twum Barimah, N. (2015). Comparison of extraction methods for the determination of available phosphorus in some selected soils from the Eastern region of Ghana [Doctoral dissertation].

Uddin, M. N., Bokelmann, W., \& Dunn, E. S. (2017). Determinants of farmers' perception of climate change: A case study from the coastal region of Bangladesh. American Journal of Climate Change, 6, 151-165. https://doi.org/10.4236/ajcc.2017.61009

Vardoulakis, S., Dimitroulopoulou, C., Thornes, J., Lai, K. M., Taylor, J., Myers, I., \& Davies, M. (2015). Impact of climate change on the domestic indoor environment and associated health risks in the UK. Environment International, 85, 299-313. https://doi.org/10.1016/ j.envint.2015.09.010

World Health Organization. (1948). Constitution of the World Health Organization. https://www.who.int/governance/ eb/who_constitution_en.pdf 